\title{
Página do Presidente
}

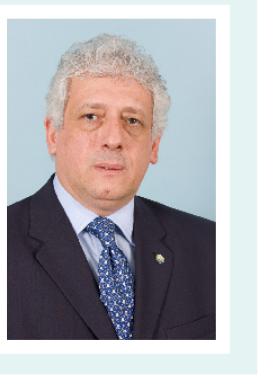

\section{Atenção à Educação Continuada de Qualidade}

\author{
Antonio Carlos Palandri Chagas \\ Presidente da SBC
}

Ingressando no nono mês à frente da nossa Sociedade Brasileira de Cardiologia (SBC), é com muito entusiasmo que inauguro esta sessão nos Arquivos Brasileiros de Cardiologia. O momento não poderia ser mais oportuno, pois coincide com a realização da $63^{\underline{a}}$ edição do Congresso Brasileiro de Cardiologia.

Quando assumi o mandato de presidente, em minha primeira mensagem aos associados, então no Jornal SBC, aceitei também, junto aos demais membros da atual diretoria, a responsabilidade de dar grande atenção à educação continuada de qualidade. Acredito que assegurar a difusão do conhecimento, ao mesmo tempo em que se estimula a produção científica, é uma das principais tarefas das sociedades de especialistas no nosso tempo.

São várias as iniciativas com esse objetivo, entre elas a renovação dos cursos de reciclagem que garantiu a oferta de treinamento homogêneo a todas as regionais da SBC. Mas, naturalmente, o congresso anual, é a que mais se destaca. Antes mesmo de sua realização, posso afirmar que estamos diante do maior fórum científico organizado por esta entidade.

Serão 30 conferências - 17 internacionais e 13 nacionais, situação quase equânime e que valoriza a bagagem científica dos pesquisadores brasileiros. E ainda: 49 mesas redondas, 29 colóquios, 37 sessões "como eu faço", dois casos clínicos, 41 controvérsias, 28 atualizações curriculares, 13 sessões especiais e 65 de temas livres orais, contemplando 660 apresentações, e três dias de apresentações de temas livres murais, incluindo quatro sessões especiais com os melhores.

As conferências de abertura e magna serão proferidas por Velentin Fuster, especialista em aterosclerose, tema central do $63^{\circ}$ congresso. A escolha desse assunto não é em vão: a aterosclerose é uma afecção crônico-degenerativa que produz, em países de primeiro e terceiro mundo, níveis considerado epidêmicos em termo de prevalência e, portanto, de grande impacto epidemiológico.

O tema central será amplamente discutido, sem o congresso perder de vista, contudo, todas as outras doenças quem acometem o aparelho cardiovascular, sobretudo as que têm maior prevalência no nosso país como a febre reumática e a doença de Chagas.

Essa primeira, por exemplo, merece fórum especial nas atividades científicas apoiadas pelo Ministério da Saúde e corrobora ação da SBC que reúne força-tarefa, com apoio do Governo federal e das sociedades congêneres de Reumatologia e Pediatria, para prevenção e tratamento dessa moléstia cardiovascular. Entre as ações da força-tarefa liderada pela SBC está a publicação de diretriz sobre a doença que representa um problema de saúde público.

A febre reumática faz 500 mil novas vítimas e causa 350 mil mortes por ano, quase exclusivamente nos países em desenvolvimento, segundo dados da Organização Mundial de Saúde (OMS). Em nível nacional, estatísticas do Sistema Único de Saúde (SUS) registram, ao longo de 24 meses, 2.207 internações na região Norte; 7.920 no Nordeste; 12.369 no Sudeste; 5.260 no Sul e mais 2.075 no Centro-Oeste, que custaram aos cofres públicos R\$162 milhões no atendimento e tratamento. Considerando as intervenções clínicas e cirúrgicas, o gasto pode ultrapassar R $\$ 390$ milhões.

A doença de Chagas também será contemplada com ênfase, durante o congresso, tendo

Correspondência: Antonio Carlos Palandri Chagas ${ }^{\circ}$

Avenida Marechal Câmara, 160/330, Centro - 20020-907, Rio de Janeiro, RJ - Brasil

E-mail: acchagas@cardiol.br 
sido reservado ao tema a conferência "Tratamento etiológico na moléstia de Chagas", entre outras atividades. Em 2009, comemora-se o ano de centenário de descoberta da moléstia e nós já estamos desenvolvendo os projetos para marcar a data. Haverá ainda um fórum, durante as atividades pré-congresso, sobre Epidemiologia e Cardiologia baseada em Evidências - uma parceria entre a SBC, através de seu gruo de estudo na área, e o Ministério da Saúde.

Além da abrangência generalizada no que se referem aos temas abordados, em 2008, a Comissão Executiva e Científica do Congresso, presidida pelo diretor Científico, Luiz Antonio de Almeida Campos, preocupou-se de maneira intensa com a co-participação efetiva dos nossos departamentos, grupos de estudos, estaduais e regionais para produzir um programa denso e abrangente que reflita os conhecimentos contemporâneos sobre as doenças cardiovasculares.

Volto novamente ao momento da posse quando declarei o propósito de congregar todos os cardiologistas para somar forças e levar a SBC a um novo momento da sua história. Desde então, todas as lideranças desta entidade são estimuladas a compartilhar conosco as decisões que ditarão os caminhos a serem trilhados. Muito além disso, especificamente em relação às estaduais e regionais, procuramos aproximar-nos de nossos representantes, conhecendo suas necessidades e dando apoio para o desenvolvimento da cardiologia em todos os territórios da nação, oferecendo, por exemplo, educação continuada a todos os cardiologistas da federação.

Esses parceiros - incluindo-se aí departamentos e grupos de estudos - aprovam integralmente a grade científica do
63ํㅡㄹ Congresso Brasileiro, tanto em relação aos temas quanto aos palestrantes, caracterizando-o como um evento de representação nacional. Além da coerência federativa em sua programação, o fórum também evidencia a internacionalização da cardiologia brasileira.

Prova disso são o II Simpósio Conjunto com o American College of Cardiology (ACC) que terá três horas de duração, com as presenças dos presidentes atual e passado do ACC, além de seu diretor Científico, e.o Simpósio Luso-Brasileiro de Cardiologia. Ambos resultam da realização de eventos conjuntos bem-sucedidos nos congressos das entidades americana e portuguesa. Cabe mencionar ainda o simpósio em parceria com a World Heart Federation (WHF), promovido no Congresso Mundial de Cardiologia.

A participação da SBC nos eventos fora do país tem-me orgulhado muito. O reconhecimento é prova de como a comunidade internacional coloca a cardiologia brasieira no mesmo patamar de qualquer outro centro de referência. $E$ continuaremos a investir em projetos que consolidem, de modo ainda mais nítido, nossa posição de liderança dentro do cenário cardiológico mundial.

Estamos abrindo as fronteiras da cardiologia, vislumbrando a internacionalização da nossa sociedade. A globalização da especialidade nacional é meta a ser perseguida, tanto que, para 2009, está sendo traçado um plano de ações para que a SBC possa liderar a cardiologia sul-americana e, por conseguinte, trazer ao Congresso Brasileiro de Cardiologia simpósios com as principais sociedades localizadas nessa região do continente. 